\title{
Optimization of Friction Surfacing Process Parameters for AA1100 Aluminum Alloy Coating with Mild Steel Substrate Using Response Surface Methodology (RSM) Technique
}

\author{
V. Sugandhi \\ Department of Manufacturing Engineering \\ Annamalai University, Annamalai Nagar 608002, Tamilnadu, India \\ Tel: 91-41-4423-9734 E-mail: sugiyogi2008@yahoo.com \\ V. Ravishankar \\ Department of Manufacturing Engineering \\ Annamalai University, Annamalai Nagar 608002, Tamilnadu, India \\ Tel: 91-41-4423-9734 E-mail: pravicdm@yahoo.co.in
}

Received: October 8, 2010

Accepted: January 10, 2012 Published: Feburary 1, 2012

doi:10.5539/mas.v6n2p69

URL: http://dx.doi.org/10.5539/mas.v6n2p69

\begin{abstract}
Friction surfacing was attempted with aluminum on a mild steel substrate. This paper focuses on the development of empirical relationship for the prediction of coating width, coating thickness of friction surfaced materials. Experimental part of the study is based on five level central composite designs of three process parameters. In order to investigate the effects of input parameters on coating width and coating thickness, an empirical relationship is constructed by multiple regression analysis. Optimization of the model is carried out to study the coating width and thickness using design-expert software. Deposit geometry measurements for all the specimens space carried out and compared with the relative impact of input parameters on coating width and thickness in order to verify the measurement errors on the values of the uncertainty in estimated parameters. The results obtained show that the developed empirical relationship can be applied to estimate the effectiveness of process parameters for a given coating width and thickness.
\end{abstract}

Keywords: Friction surfacing, Central composite design, Response surface methodology, Degree of freedom, Optimization, Deposit geometry

\section{Introduction}

Surfacing engineering has gained wide importance owing to the advantages realized of them. The friction surfacing process derivative of friction welding and retains all the benefits of solid state welding, such as forged microstructures and excellent metallurgical bond. The first patent on friction welding was issued in 1941 (Klopstock H., \& Neelands A. R., 1994), and published reports on the development of friction surfacing from friction welding first appearing in 1959 (Tyager, Kh. A., 1959; Zakson, R. I., \& Turukin F. G., 1965). In this process, the coating is extremely regular and flat, without the familiar meniscus section profile experienced with fusion welding methods. The thickness of the coated layer ranges from 0.5 to $3 \mathrm{~mm}$ depending on the material and diameter of coating rod. It is characterized by fine ripples and requires $<0.1 \mathrm{~mm}$ to be removed to produce the finished surface. The friction surfacing processes have clean environment, no fumes, no spatter. It is also energy efficient because the heat is generated exactly where it is needed. During the coating cycle the applied layer of metal reaches a temperature just below its melting point whilst simultaneously undergoing severe plastic deformation. Thus, the coating is a product of a vigorous hot forging action as opposed to the casting mechanism of fusion welding and spraying processes. This important difference means that many of the defects commonly associated with fusion techniques are avoided, and dense, clean and fine microstructures with attendant excellent properties are generated. There is no dilution of the coating by the substrate and hence no need for multiple layering as is often the case with fusion processes. Further details about the process can be found elsewhere (Bedford G. M., 1990). 
The friction surfacing process has become well established with a number of commercial applications. However, the existing models explaining the major relationships between process parameters are still generic. They are based on empirical rules and theoretical assumptions that account for a limited number of cases of current commercial interest. Many of these assumptions are implicit and have not been tested by using appropriate analysis and design of experiments. Consequently there is no method of determining the accuracy and sensitivity when changes in the process parameters are made (Bedford G. M., 1995; Nicholas E. D., \& Thomas W. M., 1987).

In this paper, an empirical relationship between friction surfacing parameters and deposit geometry was constructed based upon the experimental dada obtained by three parameters -five levels central composite design. The empirical equation, simulating the friction surfacing, was carried out by multiple regression analysis (MRA) were derived from the basic equations. This analysis generally requires a definition of an objective function and design parameters. In this study, the objective function was chosen as deposit geometry, whereas process parameters (rotational speed, frictional force, traverse speed) were selected as the design variables. The present study mainly focuses on the determination of design parameters and the prediction of fine-tuning requirements of these parameters in friction surfacing process. The results revealed considerable information about the effect of process parameters and optimum surfacing conditions.

\section{Plan of Investigation}

In order to achieve the desired aim, the present investigation was planned in the following sequence as depicted in Figure 1.

\subsection{Identifying the Important Process Parameters}

Vitanov V. I. (2000) indicated that the predominant factors which are having greater influence on deposit geometry of friction surfaced coatings were identified. They are: (i) Rotational speed $(\mathrm{N})$ in rpm, (ii) axial force (F) in $\mathrm{N} / \mathrm{mm}^{2}$ (frictional force), (iii) traverse speed (V) in $\mathrm{mm} / \mathrm{sec}$. These are primary process parameters contributing to the frictional heat and subsequently influencing the coating performance of friction surfaced materials.

\subsection{Finding the Working Limits of the Parameters}

A large number of trial runs were carried out using aluminum alloy $(22 \mathrm{~mm} \varnothing)$ coated with mild steel substrate $(150 \mathrm{~mm} \times 100 \mathrm{~mm} \times 6 \mathrm{~mm})$ to find out the feasible working limits of Friction surfacing process parameters. Chemical composition of the base metal and consumable is presented in Table 1. Trial runs were carried out by varying one of the factors while keeping the rest of them at constant values. The working range of each process parameter was decided upon by inspecting the macrostructure (cross section of friction surfaced specimens) for any visible defects. From the above inspection, the few important observations were made and they are presented in Table 2. The chosen levels of the selected process parameters with their units and notations are presented in Table 3 .

\subsection{Developing the Experimental Design Matrix}

The feasible limits of the parameters were chosen in such a way that aluminum alloy should be coated with mild steel substrate without any coating defects. Central composite rotatable design of second order was found to be the most efficient tool in response surface methodology (RSM) to establish the empirical relationship using the smallest possible number of experiments without losing its accuracy (Voutchkov I., 2001). Due to wide ranges of parameters, it was decided to use three factors, five levels, central composite design matrix to optimize the experimental conditions. Table 4 shows the 20 set of coded conditions used to form the design matrix. First experimental conditions are derived from full factorial experimental design matrix. All the variables at the intermediate $(0)$ level constitute the center points while the combinations of each process variable either at lowest (-2) or it highest (+2) with the other three variables of the intermediate levels constitute the star points. The method of designing such matrix is dealt elsewhere (Gunaraj V., 2004; Gunaraj V., \& Murugan N., 1999). For the convenience of recording and processing experimental data, upper and lower levels of the factors were coded as +2 and -2 respectively. The coded values of any intermediate value can be calculated, using the following relationship.

Where,

$$
\mathrm{Xi}=2[2 \mathrm{X}-(\mathrm{Xmax}+\mathrm{Xmin})] /(\mathrm{Xmax}-\mathrm{Xmin})
$$

$\mathrm{Xi}$ is the required coded value of a variable $\mathrm{X}$;

$\mathrm{X}$ is any value of the variable from $\mathrm{Xmin}$ to $\mathrm{Xmax}$; 
$\mathrm{Xmin}$ is the lower level of the variable;

Xmax is the highest level of the variable.

\subsection{Conducting the Experiments and Recording the Responses}

The friction surfaced aluminum coating was performed on mild steel substrate (Figure 2) as per the conditions dictated by the design matrix (Table 4). Coating thickness, coating width was measured and they are presented in Table 4.

\subsubsection{Coating Preparation}

Friction surfacing was carried out by varying the parameters as prescribed by the design matrix and aluminium coating was produced over mild steel substrate. The friction surfaced specimens, coated rod (before and after), are shown in Figures 3.

\subsubsection{Deposit Geometry Measurement}

Deposit geometry measurements for all the specimens were carried out by optical profile projector (make: meterz, India) samples where cut in the required size. The friction surfaced specimens are shown in Figures 4.

\section{Developing a Empirical Relationship}

The coating characteristics of aluminum is represented by $\mathrm{Y}$, then the response function can be expressed as

$$
\mathrm{Y}=\mathrm{f}(\mathrm{F}, \mathrm{N}, \mathrm{V})
$$

The model selected was a second degree response expressed as follows

$$
\mathrm{Y}=\mathrm{B} 0+\mathrm{B}(\mathrm{F})+\mathrm{B} 2(\mathrm{~N})+\mathrm{B} 3(\mathrm{~V})+\mathrm{B} 11(\mathrm{~F} 2)+\mathrm{B} 22(\mathrm{~N} 2)+\mathrm{B} 33(\mathrm{~V} 2)+\mathrm{B} 12(\mathrm{~F} * \mathrm{~N})+\mathrm{B} 13(\mathrm{~F} * \mathrm{~V})+\mathrm{B} 23(\mathrm{~N} * \mathrm{~V})
$$

The values of the coefficient were calculated by regression with the help of the following equations. The final model was developed after determining the significant coefficient, which lead the following test.

Coating thickness:

$$
\mathrm{Ct}=0.84+0.26 * \mathrm{~F}+0.04 * \mathrm{~N}+0.86 * \mathrm{~V}-0.01 * \mathrm{~F} * \mathrm{~N}-0.0625 * \mathrm{~F} * \mathrm{~V}+0.0375 * \mathrm{~N} * \mathrm{~V}+0.017 * \mathrm{~F} 2+0.08 * \mathrm{~N} 2+0.01 * \mathrm{~V} 2
$$

Coating width:

$$
\mathrm{Cw}=24.01+0.79 * \mathrm{~F}+0.42 * \mathrm{~N}+1.05 * \mathrm{~V}-0.9 * \mathrm{~F} * \mathrm{~N}-1.96 * \mathrm{~F} * \mathrm{~V}+0 * \mathrm{~N} * \mathrm{~V}-1.82 * \mathrm{~F} 2-1.66 * \mathrm{~N} 2-0.93 * \mathrm{~V} 2+0.1 * \mathrm{~V} 2
$$

\subsection{Checking the Adequacy of Model}

The adequacy of the model was checked using the analysis of variance (ANOVA) technique. As per the technique, if the calculated value of the ' $F$ ' ratio for the desired level of confidence (say 99\%). Then the model is conducted to the adequacy limit using the developed model for various mechanical and metallurgical properties. The predicted results of different combination are presented in the graphical form. ANOVA test result presented in the Table 5.

\subsection{Effect of Process Parameters on Deposit Geometry}

\subsubsection{Effect of Rotational Speed on Deposit of Coating}

The deposit tended to be greater in thickness with increasing rotational speed of consumable rod, regardless of the traverse speed and axial force. This might be due to an increase in torque during friction with demand rotational speed and due to an increase in the thickness of deposit because of an increased rate of deformation of consumable rod.

\subsubsection{Effect of Axial Force on Deposit of Coating}

The effect of axial force on the thickness of deposit decreased with increasing rotational speed of consumable rod, making the thickness of deposit almost uniform of the rotational speed.

\subsubsection{Effect of Traverse Speed on Deposit of Coating}

The width of the deposit tented to decrease with increased rotational speed and traverse speed on consumable rod. But it has almost uniform under the conditions of the rotation of consumable rod was slow, because effect of the traverse speed was limited. This might be because width of the deposit may be decreased by a decrease in the closure area of substrate and consumable rod. The effect of traverse speed on the thickness of deposit was demand with increasing rotational speed of consumable rod, making the thickness of deposit almost uniform at rotational speed. 


\section{Optimising the Parameters}

Contour plots show distinctive circular shape indicative of possible independence of factor with response (Figure 5). A contour plot is produced to visually display the region of optimal factor settings. For second order response surface, such a plot can be more complex than the simple series of parallel lines that can occur with first order models. Once the stationary point is found, it is usually necessary to characterize the response surface in the immediate vicinity of the point. Characterization means, identifying whether the stationary point found is a maximum response or minimum response or a saddle point. To classify this, the most straightforward way is to examine through a contour plot. Contour plots play a very important role in the study of the response surface. By generating contour plots using software for response surface analysis, the optimum value is located with reasonable accuracy by characterizing the shape of the surface.

If a contour patterning of circular shaped contours occurs, it tends to suggest independence of factor effects while elliptical contours as may indicate factor interactions. Response surfaces have been developed for both the models, taking two parameters in the middle level and two parameters in the $\mathrm{X}$ and $\mathrm{Y}$ axis and response in $\mathrm{Z}$ axis. The response surfaces are clearly revealing the optimal response point. RSM is used to find the optimal set of process parameters that produce a maximum or minimum value of the response. In the present investigation the process parameters corresponding to the minimum coating thickness are considered as optimum (by analyzing the contour graphs and by solving the equation 4 and 5). Hence, when these optimized process parameters are used, then it will possible to attain the minimum coating thickness.

The presented three dimensional response surface plots for the response coating thickness obtained from the regression model. The optimum coating thickness is exhibited by the apex of the response surface exhibits almost a circular contour, which suggests independence of factor effect namely rotational speed. It is relatively easy by examining the contour plots that changes in the coating thickness are more sensitive to changes in rotational speed than to changes in axial force and traverse speed. Interaction effect between the combination of factors such as rotational speed and traverse speed, rotational speed and axial force and traverse speed and axial force on coating thickness and coating width also exists (Figure 6), which is evidenced from the contour plots. Increase in rotational speed resulted in increase of coating width and coating thickness is decreased.

Predicted optimum coating thickness obtained from the response surface and contour plots by using a combination of axial force $14 \mathrm{~N} / \mathrm{mm}^{2}$, rotational speed $2500 \mathrm{rpm}$ and traverse speed $16 \mathrm{~mm} / \mathrm{sec}$, which resulted in a coating thickness of 0.89 and coating width $20.22 \mathrm{~mm}$. To demonstrate the validity of the model, actual experiments were conducted at the optimum values of process parameters to make a coating. The above values were also verified using statistical software Minitab.

\section{Conclusions}

Empirical relations were developed to predict coating thickness and coating width incorporating friction surfacing process parameters. The developed relationships can be effectively used to predict the coating at $95 \%$ confidence level and Friction surfacing process parameters were optimized using response surface methodology to attain minimum thickness and maximum width. The optimum conditions are: axial force $14 \mathrm{~N} / \mathrm{mm}^{2}$, rotational speed $2500 \mathrm{rpm}$ and traverse speed $16 \mathrm{~mm} / \mathrm{sec}$.

\section{References}

Bedford, G. M. (1990). Friction surfacing for wear application. Metals mater, 6(11), 702-705.

Bedford, G. M., Ward, L. J., Tooley, P. J., Wilson, B. J., \& Sharp, R. J. (1995). Large scale friction surfacing. In Proceeding of the EUROMAT'95 4th European Conference on Advanced Materials and processes, Italy, September, 441-444.

Douglas, C. M. (2007). Design and analysis of experimentas. John Wiley \& Sons, New York.

Gunaraj, V., \& Murugan, N. (1999). Application of response surface methodology for predicting weld bead quality in submerged arc welding of pipes. Journals of materials processing technology, 88, 266-275.

Klopstock, H., \& Neelands, A. R. (1994). An improved method of joining and welding metals. Patent specifiction, No. 572789, U.K.

Nicholas, E. D., \& Thomas, W. M. (1987). Metal deposition by friction welding. Welding J., 7, 17-27.

Tokiwue, Hiroshi, Katoh, Kazuyoshi, Asahina, Toshikatsu, Ushiyama, \& Toshio. (2004). Mechanical properties of 5052/2017 dissimilar aluminum alloys deposit by friction surfacing. Journal of Japan institute of light metals, 54(9), 373-379. 
Tyager, Kh. A. (1959). Friction welding in the reconditiong of worn component. Weldprod, 10(1), 23-24.

Voutchkov, I., Jawaorsk, Bb., IVitanov, V., \& Bedford, G. M. (2001). An integrated approach to friction surfacing process optimization. Surface and coatings technology, 141, 26-33. http://dx.doi.org/10.1016/S0257-8972(01)01127-6

Vitanov, V. I., Voutchkov, I. I., \& Bedford, G. M. (2000). Decision support system to optimize the frictec (friction surfacing) process. Journal of materials processing technology, 107, 236-2. http://dx.doi.org/10.1016/S0924-0136(00)00710-X

William, G. C., \& Gertrude, M. C. (1957). Experimental designs. John Wiley \& Sons, Inc., London.

Zakson, R. I., \& Turukin, F. G. (1965). Friction welding and hard facing of agricultural machine parts, Avt svarka, $3,48-50$.

Table 1. Chemical composition (wt \%) of base metal

\begin{tabular}{|l|l|l|l|l|l|l|l|l|l|l|l|l|l|}
\hline S.No & Material & $\mathrm{Al}$ & $\mathrm{C}$ & $\mathrm{Mn}$ & $\mathrm{Mg}$ & $\mathrm{Zn}$ & $\mathrm{Fe}$ & $\mathrm{Si}$ & $\mathrm{P}$ & $\mathrm{Cr}$ & $\mathrm{Ni}$ & $\mathrm{Ti}$ & $\mathrm{Cu}$ \\
\hline 1 & $\begin{array}{l}\text { Mild } \\
\text { Steel }\end{array}$ & - & 0.07 & 0.31 & - & - & $\mathrm{Bal}$ & 0.31 & 0.089 & & 0.11 & - & 0.24 \\
\hline 2 & $\begin{array}{l}\text { AA } \\
1100\end{array}$ & Bal & - & 0.004 & 0.0015 & 0.0016 & 0.508 & 0.152 & & 0.006 & - & 0.015 & 0.061 \\
\hline
\end{tabular}


Table 2. Macrostructure observations of the friction surfaced specimens

\begin{tabular}{|c|c|c|c|}
\hline Input parameters & Parameter range & Macrostructure & Probable reason \\
\hline Rotational speed & $<2000 \mathrm{rpm}$ & & $\begin{array}{c}\text { In sufficient } \\
\text { frictional heat and In } \\
\text { sufficient metal } \\
\text { deposition }\end{array}$ \\
\hline Rotational speed & $>3000 \mathrm{rpm}$ & & $\begin{array}{c}\text { Further Increase less } \\
\text { deposition }\end{array}$ \\
\hline Axial force & $<10 \mathrm{~N} / \mathrm{mm}^{2}$ & & $\begin{array}{l}\text { In sufficient Axial } \\
\text { force and in } \\
\text { adequate heat } \\
\text { generation }\end{array}$ \\
\hline Axial force & $>18 \mathrm{~N} / \mathrm{mm}^{2}$ & & $\begin{array}{l}\text { Additional axial } \\
\text { force lards to excess } \\
\text { heat input and } \\
\text { thinning of the metal } \\
\text { deposited }\end{array}$ \\
\hline Traverse speed & $<10 \mathrm{~mm} / \mathrm{sec}$ & & $\begin{array}{c}\text { Low frictional heat } \\
\text { Generated }\end{array}$ \\
\hline Traverse speed & $>30 \mathrm{~mm} / \mathrm{sec}$ & & $\begin{array}{l}\text { Increase in traverse } \\
\text { speed resulted in } \\
\text { Poor Plasticization } \\
\text { on associated defect }\end{array}$ \\
\hline
\end{tabular}

Table 3. Important factors and their level

\begin{tabular}{|c|c|c|c|c|c|c|c|c|}
\hline \multirow{2}{*}{ S.NO } & \multirow{2}{*}{ Factors } & \multirow{2}{*}{ Notation } & \multirow{2}{*}{ Unit } & \multicolumn{5}{|c|}{ Factor Levels } \\
\cline { 4 - 8 } & & & & -2 & -1 & 0 & 1 & 2 \\
\hline 1 & Axial force & $\mathrm{F}$ & $\mathrm{N} / \mathrm{mm}^{2}$ & 10 & 12 & 14 & 16 & 18 \\
2 & Rotational speed & $\mathrm{N}$ & $\mathrm{rpm}$ & 2000 & 2250 & 2500 & 2750 & 3000 \\
3 & Traverse speed & $\mathrm{V}$ & $\mathrm{Mm} / \mathrm{sec}$ & 10 & 15 & 20 & 25 & 30 \\
\hline
\end{tabular}


Table 4. Design Matrix and experimental result

\begin{tabular}{|c|c|c|c|c|c|}
\hline Ex .no & $\begin{array}{c}\text { Rotational } \\
\text { speed }(\mathrm{rpm})\end{array}$ & $\begin{array}{l}\text { Traverse } \\
\text { speed } \\
(\mathrm{mm} / \mathrm{sec})\end{array}$ & $\begin{array}{l}\text { Axial } \\
\text { force } \\
(\mathrm{k} \mathrm{N})\end{array}$ & $\begin{array}{l}\text { Coating } \\
\text { thickness } \\
(\mathrm{mm})\end{array}$ & $\begin{array}{l}\text { Coating } \\
\text { width } \\
(\mathrm{mm})\end{array}$ \\
\hline 1 & -1 & -1 & -1 & 1.37 & 25.46 \\
2 & +1 & -1 & -1 & 2.43 & 26.08 \\
3 & -1 & +1 & -1 & 1.60 & 20.47 \\
4 & +1 & +1 & -1 & 2.23 & 23.27 \\
5 & -1 & -1 & +1 & 2.37 & 26.84 \\
6 & +1 & -1 & +1 & 2.43 & 29.08 \\
7 & -1 & +1 & +1 & 1.30 & 25.82 \\
8 & +1 & +1 & +1 & 0.7 & 24.64 \\
9 & -2 & 0 & 0 & 2.23 & 28.22 \\
10 & +2 & 0 & 0 & 0.7 & 23.38 \\
11 & 0 & -2 & 0 & 1.8 & 24.64 \\
12 & 0 & +2 & 0 & 1.2 & 24.64 \\
13 & 0 & 0 & -2 & 2.4 & 20.26 \\
14 & 0 & 0 & +2 & 1.36 & 27.96 \\
15 & 0 & 0 & 0 & 2.3 & 25.94 \\
16 & 0 & 0 & 0 & 2.6 & 24.92 \\
17 & 0 & 0 & 0 & 2.8 & 23.42 \\
18 & 0 & 0 & 0 & 2.4 & 25.82 \\
19 & 0 & 0 & 0 & 2.6 & 27.96 \\
20 & 0 & 0 & 0 & 2.93 & 27.16 \\
\hline
\end{tabular}


Table 5. ANOVA result for the deposit geometry

\begin{tabular}{|c|c|c|c|c|c|c|}
\hline Source & $\begin{array}{l}\text { Sum of } \\
\text { Squares }\end{array}$ & $\mathrm{df}$ & Mean Square & F Value & $\begin{array}{l}\text { p-value } \\
\text { Prob }>\text { F }\end{array}$ & \\
\hline Model & 1.299866 & 9 & 0.14443 & 27.13377 & $<0.0001$ & \multirow[t]{11}{*}{ Significant } \\
\hline A-A & 0.911007 & 1 & 0.911007 & 171.1495 & 0.0001 & \\
\hline B-B & 0.026761 & 1 & 0.026761 & 5.027479 & 0.0488 & \\
\hline $\mathrm{C}-\mathrm{C}$ & 0.100156 & 1 & 0.100156 & 18.81611 & 0.0015 & \\
\hline $\mathrm{AB}$ & 0.0008 & 1 & 0.0008 & 0.150295 & 0.7064 & \\
\hline $\mathrm{AC}$ & 0.03125 & 1 & 0.03125 & 5.87089 & 0.0359 & \\
\hline $\mathrm{BC}$ & 0.01125 & 1 & 0.01125 & 2.11352 & 0.1767 & \\
\hline $\mathrm{A} 2$ & 0.004323 & 1 & 0.004323 & 0.81213 & 0.3887 & \\
\hline $\mathrm{B} 2$ & 0.094457 & 1 & 0.094457 & 17.74548 & 0.0018 & \\
\hline $\mathrm{C} 2$ & 0.145281 & 1 & 0.145281 & 27.29375 & 0.0004 & \\
\hline Residual & 0.053229 & 10 & 0.005323 & & & \\
\hline Lack of Fit & 0.042095 & 5 & 0.008419 & 3.781023 & 0.0854 & \multirow{7}{*}{$\begin{array}{c}\text { Not } \\
\text { significant }\end{array}$} \\
\hline Pure Error & 0.011133 & 5 & 0.002227 & & & \\
\hline Cor Total & 1.353095 & 19 & & & & \\
\hline Std. Dev. & 0.072958 & & R-Squared & 0.960661 & & \\
\hline Mean & 0.9805 & & $\begin{array}{c}\text { Adj } \\
\text { R-Squared } \\
\end{array}$ & 0.925257 & & \\
\hline C.V.\% & 7.4409 & & $\begin{array}{c}\text { Pred } \\
\text { R-Squared }\end{array}$ & 0.751144 & & \\
\hline PRESS & 0.336726 & & $\begin{array}{c}\text { Adeq } \\
\text { Precision }\end{array}$ & 18.16749 & & \\
\hline Model & 148.8797 & 9 & 16.54218 & 43.40183 & $<0.0001$ & \multirow{23}{*}{ Significant } \\
\hline A-Axial force & 8.530598 & 1 & 8.530598 & 22.38178 & 0.0008 & \\
\hline $\begin{array}{c}\text { B-Rotational } \\
\text { Speed }\end{array}$ & 2.405248 & 1 & 2.405248 & 6.310663 & 0.0308 & \\
\hline $\begin{array}{c}\text { C-traverse } \\
\text { speed }\end{array}$ & 15.14118 & 1 & 15.14118 & 39.726 & $<0.0001$ & \\
\hline $\mathrm{AB}$ & 6.6248 & 1 & 6.6248 & 17.38153 & 0.0019 & \\
\hline $\mathrm{AC}$ & 30.7328 & 1 & 30.7328 & 80.63383 & $<0.0001$ & \\
\hline $\mathrm{BC}$ & 0 & 1 & 0 & 0 & 1.000 & \\
\hline A2 & 48.2217 & 1 & 48.2217 & 126.5196 & $<0.0001$ & \\
\hline $\mathrm{B} 2$ & 39.60479 & 1 & 39.60479 & 103.9113 & $<0.0001$ & \\
\hline $\mathrm{C} 2$ & 12.40209 & 1 & 12.40209 & 32.53943 & 0.0002 & \\
\hline Residual & 3.811403 & 10 & 0.38114 & & & \\
\hline Lack of Fit & 1.811403 & 5 & 0.362281 & 0.905701 & 0.5420 & \\
\hline Pure Error & 2 & 5 & 0.4 & & & \\
\hline Cor Total & 152.6911 & 19 & & & & \\
\hline Source & $\begin{array}{l}\text { Sum of } \\
\text { squares }\end{array}$ & $\mathrm{df}$ & Mean Square & F Value & $\begin{array}{l}\text { p-value } \\
\text { Prob }>\text { F }\end{array}$ & \\
\hline R-Squared & 0.975038 & & & & & \\
\hline $\begin{array}{l}\text { Adj R - } \\
\text { Squared }\end{array}$ & 0.952573 & & & & & \\
\hline $\begin{array}{c}\text { Pred } \\
\text { R-Squared }\end{array}$ & 0.891152 & & & & & \\
\hline $\begin{array}{c}\text { Adeq } \\
\text { Precision }\end{array}$ & 21.87096 & & & & & \\
\hline Std. Dev. & & & 0.617366 & & & \\
\hline Mean & & & 20.9965 & & & \\
\hline C.V.\% & & & 2.940326 & & & \\
\hline PRESS & & & 16.62004 & & & \\
\hline
\end{tabular}




\section{WORK PLAN}

Statement of the problem and its objectives

$\downarrow$

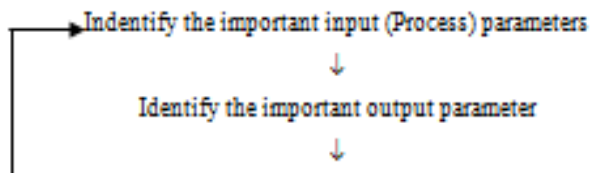

$\rightarrow$ Form literature and experiment

Find upper and lower limits for input parameters $\downarrow$

Developing the experimental designs matrix

$$
\downarrow
$$

Conducting the experiment as per design matrix and recording the response

$\downarrow$

Statistical analysis of data and development of a mathematical model by considering significant factors

$\downarrow$

Validation of the developed model $\downarrow$

$\rightarrow$ Based on application

$\rightarrow$ Based on literature prous \& knowledge (practical and.

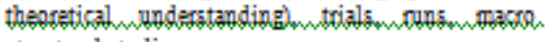
structural atudies

$\rightarrow$ Considering no. of replicates, randomize of order of experiments blocking or not etc. based on cast, time accuracy of information required and resources available

Using FSW Machine

- Selecting spitable statintical software packager ysing ANQXA graphical mothods by conducting residual analysis and by checking the adequacy. of the model.

$\rightarrow$ By conducting further experiments and comparing actual and predicted values.

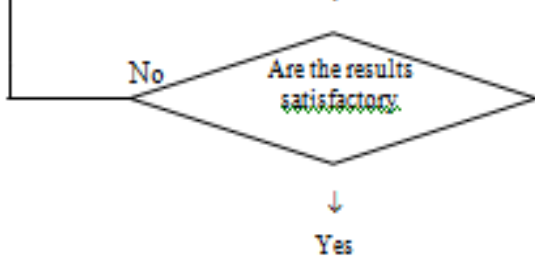

Optimize the process parameter sensitivity analysis $\downarrow$

Implementation of results $\downarrow$

Follow up

Figure 1. Work plan 


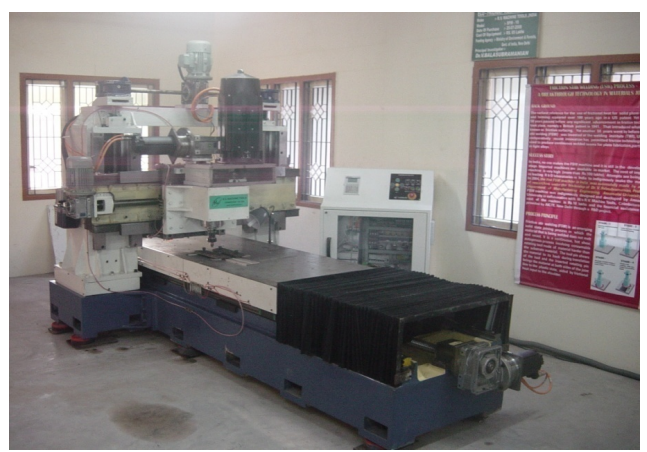

Figure 2. Friction surfacing machine

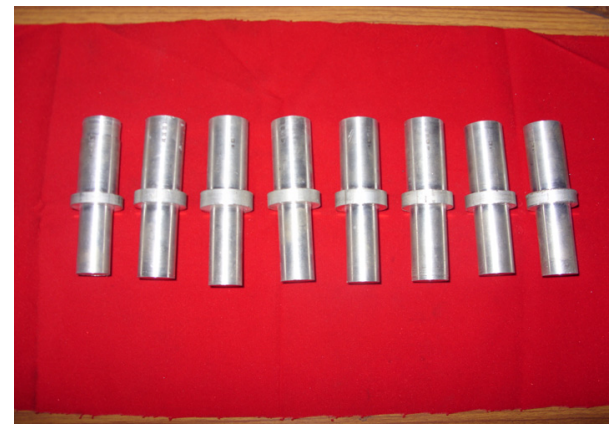

(a) before coated rod

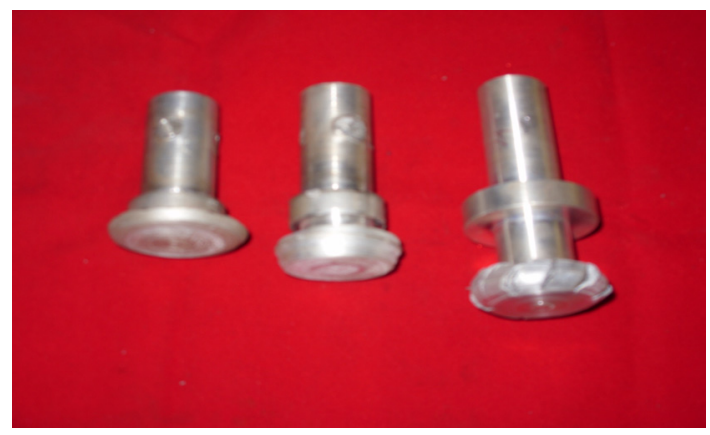

(b) after coated rod

Figure 3. The friction surfaced specimens

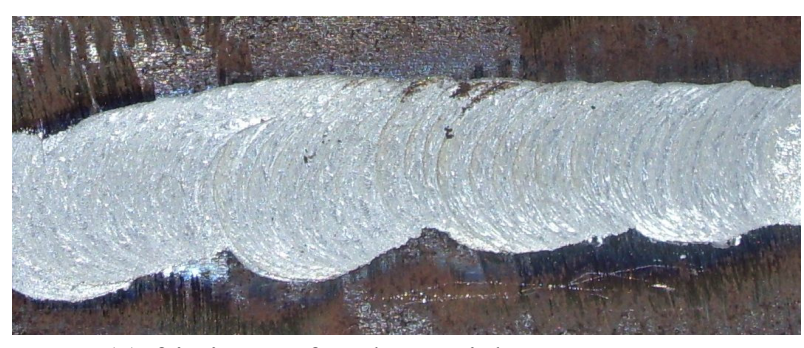

(a) friction surfaced materials

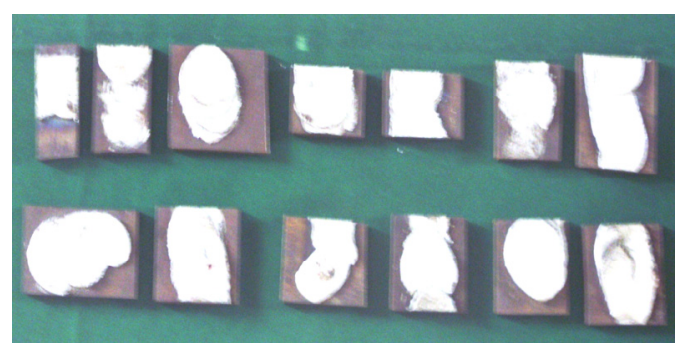

(b) friction surfaced specimens

Figure 4 . The friction surfaced specimens by deposit geometry measurements 


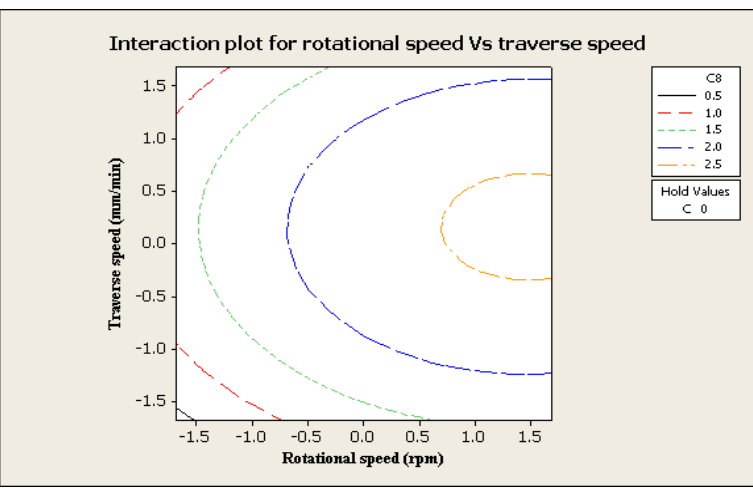

(a) Coating thickness, traverse speed Vs. rotational speed

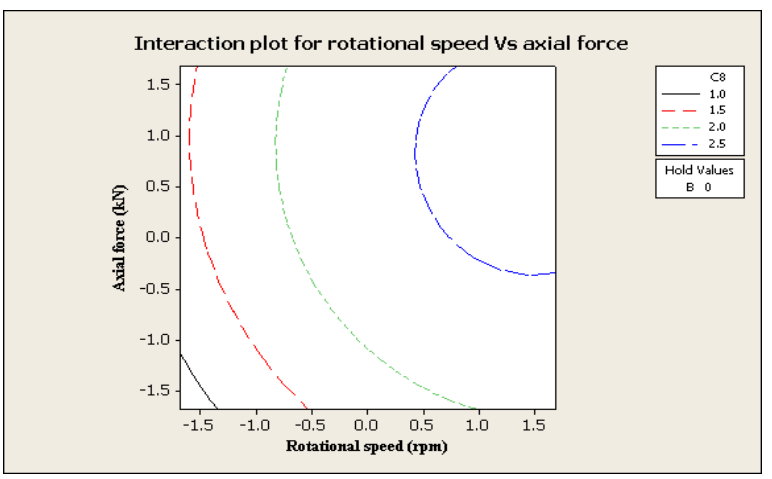

(c) Coating thickness, axial force Vs. rotational speed

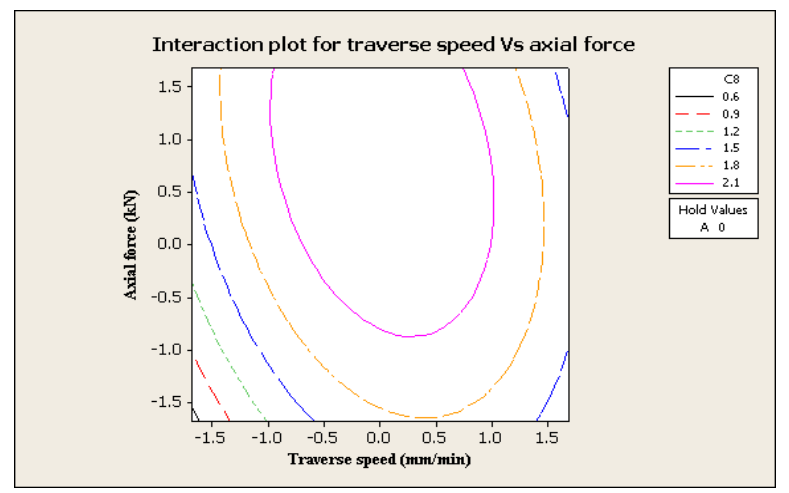

(e) Coating thickness, axial force Vs. traverse speed

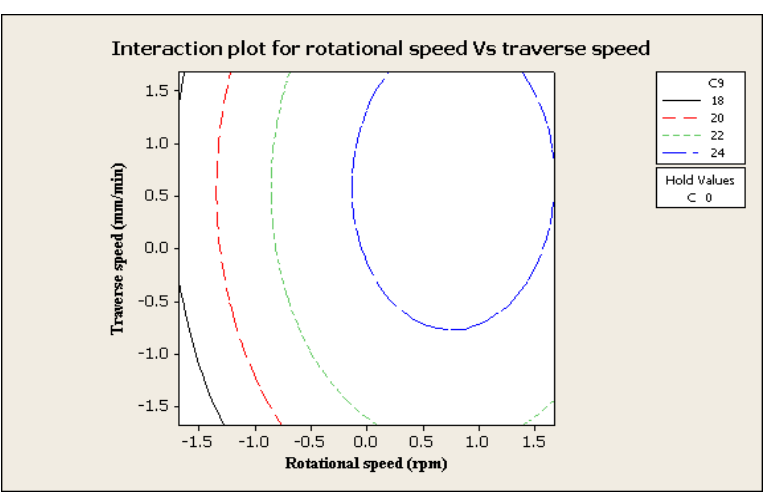

(b) Coating width, traverse speed Vs. rotational speed

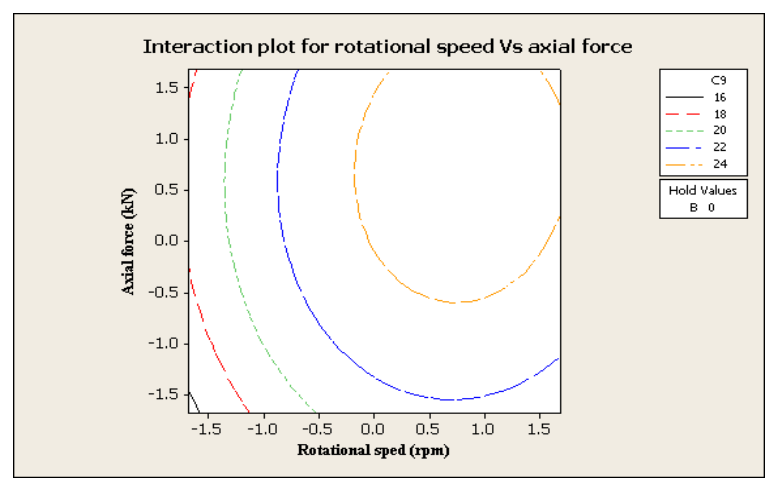

(d) Coating width, axial force Vs. rotational speed

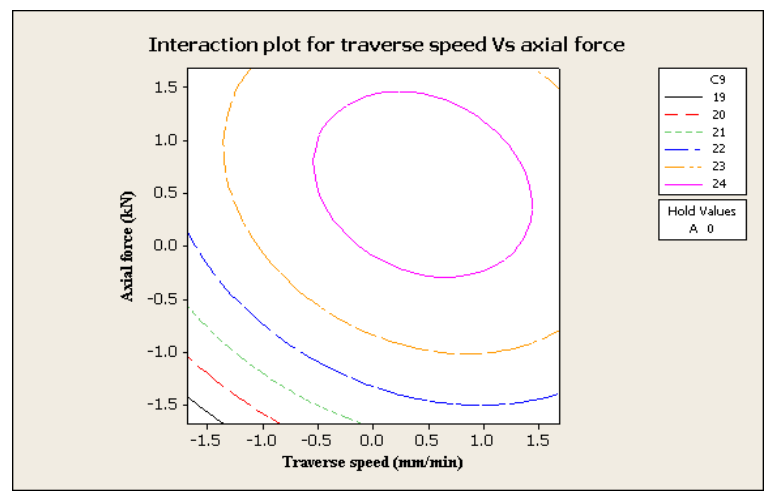

(f) Coating width, axial force Vs. traverse speed

Figure 5. Contour plot of possible independence of factor with response 


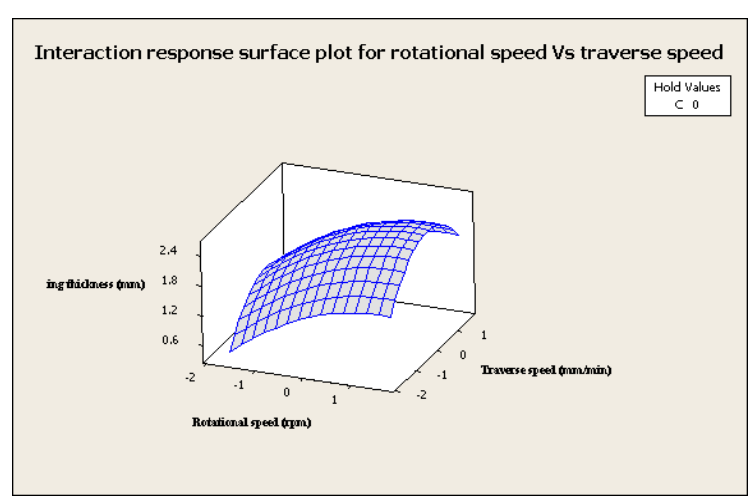

(a) Coating thickness, V vs. N

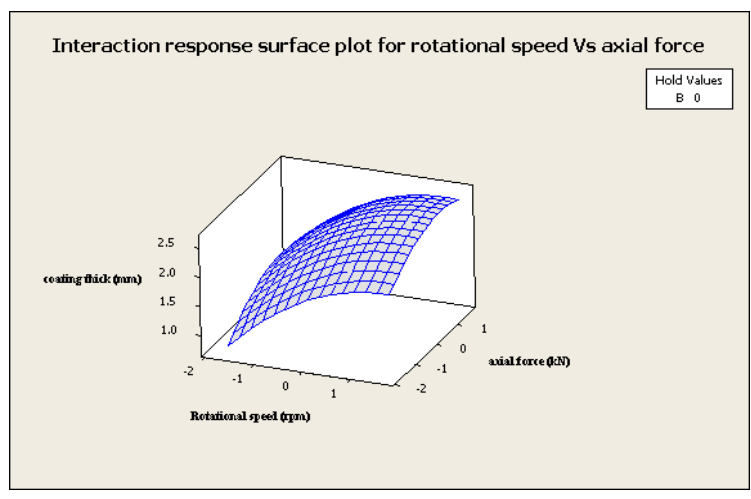

(c) Coating thickness, V vs. F

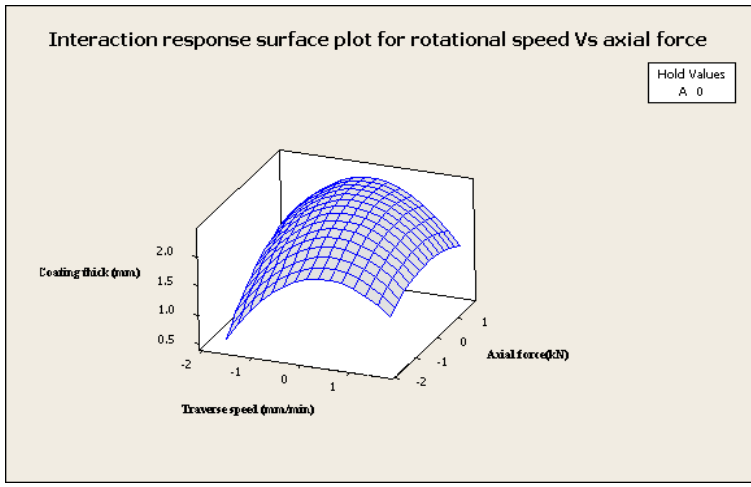

(e) Coating thickness, $\mathrm{N}$ vs. F

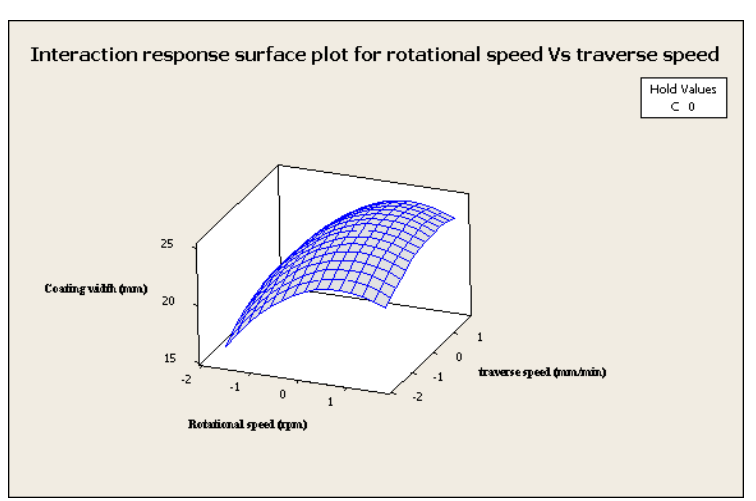

(b) Coating width, V vs. N

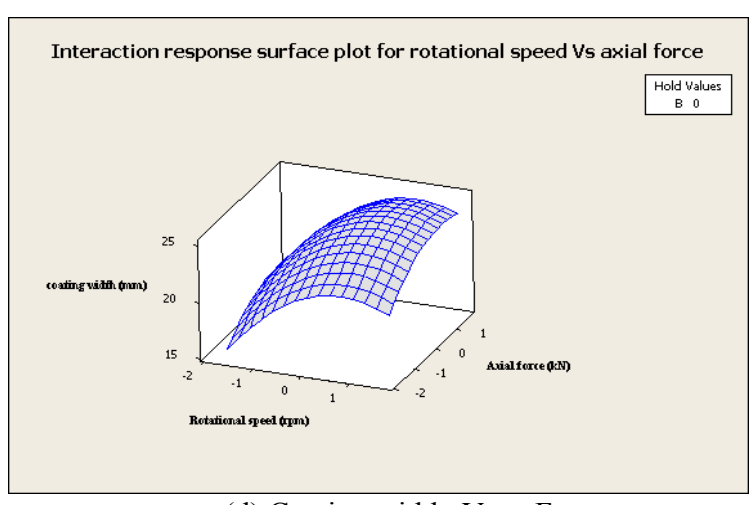

(d) Coating width, V vs. F

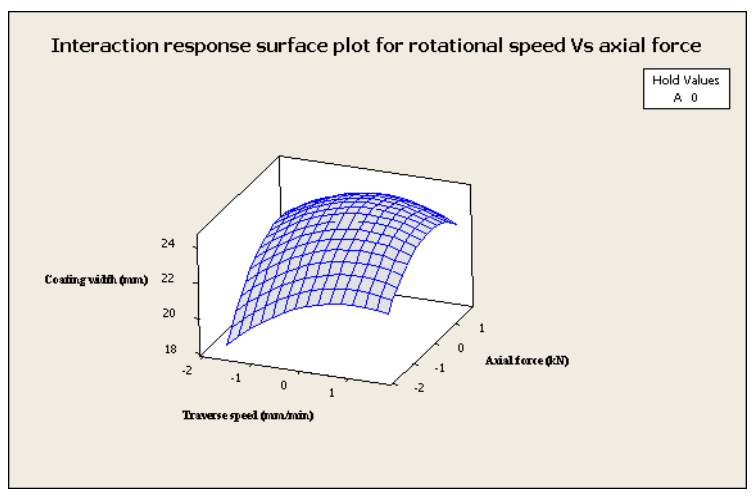

(f) Coating width, N vs. F

Figure 6. Interaction effect between the combination of factors 